\title{
Simple Home Program for Frozen Shoulder to Improve Patients' Assessment of Shoulder Function and Health Status
}

\author{
John W. O'Kane, MD, Sarah Jackins, RPT, John A. Sidles, PhD, Kevin L. Smith, MD, and \\ Frederick A. Matsen III, MD
}

Background: The purpose of this investigation was to test the hypothesis that a simple home program can improve the self-assessed shoulder function and health status of a group of patients with frozen shoulders.

Metbods: A case series using a one-group pretest, posttest design analyzing 41 patients from a single orthopedic practice who had a frozen shoulder were included in this study. The patients completed the Simple Shoulder Test (SST) and the Medical Outcomes Study Short-Form Health Survey (SF-36) questionniare at the time of initial consultation, had treatment consisting of education regarding frozen shoulder and home stretching instructions, and were asked to complete the same questionnaires mailed every 6 months. Initial results were compared with previously published control values to establish level of impairment, and followup results were compared with the initial results to determine the extent of improvement.

Results: Patients initially had serious deficits in the 12 shoulder functions inventoried by the SST and were also compromised in their general health status as reflected by the SF-36 scores. At follow-up, 4 of 10 SST functions were improved $(P<0.001)$. The SF-36 health status scores of physical function, comfort, and physical role function were also improved $(P<0.001)$.

Conclusion: These data suggest that this home program for frozen shoulder can lead to improved selfassessed shoulder function and health status in patients similar to those in the study population. (J Am Board Fam Pract 1999;12:270-7.)

It is well recognized that shoulders can become stiff without noticeable injury, previous surgery, or radiographic changes. Although the medical community has used a variety of terms, such as periarthritis or adhesive capsulitis, to describe this condition, in this article we use the term frozen sboulder to describe those shoulders in which functionally restrictive stiffness occurs without antecedent trauma or radiographic change. ${ }^{1-7} \mathrm{Cod}-$ $\operatorname{man}^{8}$ stated in 1934 that frozen shoulder was "difficult to define, difficult to treat, and difficult to explain." Since then frozen shoulder has been the subject of lively discussion within the orthope-

Submitted, revised, 19 February 1999.

From the Departments of Orthopaedics (JWO'K, JAS, KLS, FAM) and Family Medicine (JWO'K), the Department of Intercollegiate Athletics (JWO'K), and the University of Washington Exercise Training Center (SJ), University of Washington, Seattle. Address reprint requests to Frederick A. Matsen III, MD, Department of Orthopaedics, University of Washington, Box 356500, 1959 NE Pacific St, Seattle, WA 98195-6500.

This research was supported by the Bristol-Myers Squibb/Zimmer Institutional Award for Excellence in Orthopaedic Research and the E.A. Codman Research Fund at the University of Washington. dic literature. Recent retrospective studies by Miller et $\mathrm{al}^{9}$ and Shaffer et al ${ }^{10}$ suggest that patients with idiopathic frozen shoulder can improve with nonoperative treatment.

Our purpose was to conduct a prospective study to test the hypothesis that patients with frozen shoulder can obtain improvements in selfassessed shoulder function and general health status using a simple home program. The advantages of using self-assessment included convenience for the patient, minimal imposition and cost for the physician's office, and perhaps most importantly, an indication of the patient's own view of functional improvement.

\section{Methods}

From January 1992 to December 1995,58 patients seeking care from a shoulder consultant (FAM) met the diagnostic criteria for frozen shoulder: major functional restriction in the range of glenohumeral motion not related to arthritis or to previous shoulder injury or surgery. ${ }^{2,3}$ Of these patients 17 were excluded from the study, 13 because they could not be located for follow-up 
questionnaires and 4 because they were referred for surgical treatment after a protracted (greater than 6 months) unsuccessful attempt at nonoperative management. The remaining 41 patients in the study cohort met the diagnostic criteria for idiopathic frozen shoulder, were willing to have their condition treated using the home management program, and were available for follow-up.

The average age of the patients in the study cohort was 56 years (range 36 to 75 years). There were 19 men and 22 women. Six patients had bilateral frozen shoulders; in these cases one of the two shoulders was chosen randomly for inclusion in the study. There were 15 right shoulders and 27 left shoulders. There were only 4 patients who had diabetes in this study cohort. We did not find other important comorbidities in this patient population.

At the time of initial consultation, each patient completed the Simple Shoulder Test (SST) inventory of shoulder functions $s^{3,11}$ and the Medical Outcomes Study Short-Form Health Survey (SF36) questionnaire. ${ }^{12-15}$ The SST was selected because (1) it is simple, has face validity, and is reproducible ${ }^{3,11}$; (2) it is responsive to successful management of frozen shoulders ${ }^{16}$ and glenohumeral degenerative joint disease ${ }^{17}$; (3) examines function from the perspective of the patient; and (4) in contrast to shoulder-scoring systems requiring measurement of range of motion, it does not require the patient to return to the clinic for a time- and resource-consuming evaluation by office personnel. ${ }^{18,19}$

The SF-36 is a standardized self-assessment of general health status that has been used extensively throughout the medical literature for documenting patients' impressions of their own physical and mental condition. ${ }^{12,15}$ It has been found to be sensitive to the successful treatment of glenohumeral degenerative joint disease. ${ }^{17}$ The SF-36 does not contain questions specifically regarding upper extremity function; therefore, it was desirable to combine it with the SST.

The SST shoulder function inventory and the SF-36 were completed by each patient at the time of initial consultation with the senior author. The physician then discussed the frozen shoulder with the patient and answered questions. Finally, a registered therapist (SJ) taught a set of home exercises emphasizing gentle patient-conducted stretching and provided a sheet that diagrammed the exercises. The visit with the therapist took approxi- mately 15 minutes. The details of the home exercise program can be found on the World Wide Web at the following URL: <http://www.orthop.washington.edu/shoulder/shoulder.htm> (see Home Exercises - Stiffness). Hands-on therapy was not used with this series of patients.

Follow-up questionnaires were mailed to each patient every 6 months. The average follow-up period was $25 \pm 13$ months with a range from 6 to 50 months.

\section{Data Analysis \\ Shoulder Function}

Results were summarized in terms of the percentage of patients indicating they could perform each of the 12 functions evaluated by the SST. Confidence intervals and $P$ values were computed from a binomial distribution as is appropriate for a yesor-no (binary) response format. The initial shoulder function of the study cohort was compared with that of previously published control data. ${ }^{3}$ Follow-up shoulder function was compared with the initial shoulder function for the study cohort to determine whether there was significant improvement in the self-assessed functions. Finally, the net gain in percentage of patients able to perform each function was tabulated to determine which shoulder functions were improved by the home management program.

\section{Overall Health Status}

The SF-36 questionnaires were scored according to the algorithm of Ware et al, ${ }^{14,15,20}$ which yields eight health status scores: physical function, social function, physical role function, emotional role function, mental health, vitality, comfort, and general health. Scores range from 0 (the least healthy response) to 100 (the most healthy response).

The results for each SF-36 score at the time of initial examination were averaged, confidence intervals calculated, and $P$ values determined for significant difference from age- and sex-matched controls. ${ }^{21}$ SF-36 scores for each of the eight domains at the time of follow-up self-assessment were averaged, confidence intervals calculated, and $P$ values determined for the significance of improvement from the initial examination. The net change in score from initial to follow-up evaluation was also determined for each of the eight SF-36 domains along with the confidence intervals. The confidence intervals and $P$ values for the 
Table 1. Initial and Follow-up Results on Simple Shoulder Test (SST) Shoulder Function Inventory.

\begin{tabular}{|c|c|c|c|c|c|c|c|c|}
\hline \multirow[b]{2}{*}{ Function } & \multicolumn{3}{|c|}{ SST at Initial Examination } & \multicolumn{3}{|c|}{ SST at Follow-up } & \multicolumn{2}{|c|}{ Change } \\
\hline & $\begin{array}{c}\text { Percent } \\
\text { Yes }\end{array}$ & $\begin{array}{c}\text { Confidence } \\
\text { Interval }\end{array}$ & $\begin{array}{c}P \\
\text { Value }^{\dagger}\end{array}$ & $\begin{array}{c}\text { Percent } \\
\text { Yes }\end{array}$ & $\begin{array}{c}\text { Confidence } \\
\text { Interval }\end{array}$ & $\begin{array}{c}P \\
\text { Value }^{\ddagger}\end{array}$ & $\begin{array}{c}\text { Percent } \\
\text { Yes } \$\end{array}$ & $\begin{array}{c}\text { Confidence } \\
\text { Interval }\end{array}$ \\
\hline $\begin{array}{l}\text { Am comfortable at side } \\
\text { Sleep on side }\end{array}$ & $\begin{array}{l}71 \\
12\end{array}$ & $\begin{array}{l}56,85 \\
02,23\end{array}$ & $\begin{array}{l}<0.001 \\
<0.001\end{array}$ & $\begin{array}{l}95 \\
78\end{array}$ & $\begin{array}{l}88,100 \\
65,90\end{array}$ & $\begin{array}{r}0.003 \\
<0.001\end{array}$ & $\begin{array}{l}24 \\
66\end{array}$ & $\begin{array}{l}09,40 \\
51,81\end{array}$ \\
\hline Tuck in back of shirt & 39 & 23,55 & $<0.001$ & 88 & 78,98 & $<0.001$ & 49 & 30,68 \\
\hline Place hand behind head & 51 & 35,67 & $<0.001$ & 88 & 78,98 & $<0.001$ & 37 & 20,54 \\
\hline Place coin on shelf & 68 & 53,83 & $<0.001$ & 90 & 80,98 & 0.005 & 22 & 07,37 \\
\hline Place $1 \mathrm{lb}$ on shelf & 71 & 56,85 & $<0.001$ & 83 & 70,93 & 0.058 & 12 & 00,25 \\
\hline Place $8 \mathrm{lb}$ on shelf & 24 & 11,38 & $<0.001$ & 56 & 40,70 & 0.002 & 32 & 13,51 \\
\hline Carry $20 \mathrm{lb}$ at side & 63 & 48,79 & $<0.001$ & 66 & 50,80 & 0.743 & 2 & $-13,17$ \\
\hline Toss underhand & 54 & 38,70 & $<0.001$ & 73 & 60,88 & 0.019 & 20 & 03,36 \\
\hline Toss overhand & 15 & 03,26 & $<0.001$ & 46 & 30,63 & $<0.001$ & 32 & 15,48 \\
\hline Wash back of shoulder & 15 & 03,26 & $<0.001$ & 76 & 63,88 & $<0.001$ & 61 & 44,78 \\
\hline Allow regular work & 56 & 40,72 & $<0.001$ & 78 & 65,90 & 0.018 & 22 & 04,40 \\
\hline \multicolumn{9}{|c|}{$\begin{array}{l}\text { Note: The first three columns display significant reduction in shoulder function of patients with frozen shoulder compared with normal } \\
\text { patients. The second three columns display shoulder function of patients at follow-up and significance of increase in percentage who } \\
\text { could perform these functions. The final pair of columns displays net change in number of patients who could perform each shoulder } \\
\text { function. } \\
\text { " } 95 \% \text { confidence intervals for the estimated mean (binomial distribution). } \\
{ }^{\dagger} P \text { value that in the SST answers at initial examination are no worse than control (binomial distribution). } \\
\ddagger P \text { value that in the SST follow-up scores are unchanged relative to initial examination (binomial distribution). } \\
\text { \$Percentage of patients changing "no" to "yes" (favorable response) minus percentage changing "yes" to "no" (unfavorable response). }\end{array}$} \\
\hline
\end{tabular}

SF-36 were determined by the $t$ test. As a consistency check, we also computed $P$ values using the Wilcoxon signed rank test, which yielded essentially identical results.

A Mann-Whitney $U$ test was used to determine whether there were significant differences in improvement in the health status or shoulder function of patients observed for less than 25 months in comparison with those observed for more than 25 months. An attempt was also made to determine whether any particular comorbidities, such as diabetes, age, sex, smoking, or bilateral involvement, were associated with better or worse results subsequent to the home treatment program.

\section{Results}

\section{Initial Evaluation}

Shoulder Function

The SST shoulder function inventory indicated substantial functional deficits at the time patients were initially evaluated for frozen shoulder. Whereas normal patients indicated they were able to perform essentially all 12 SST functions, ${ }^{3} \mathrm{pa}-$ tients in this cohort with frozen shoulders showed statistically significant compromise of all 12 shoulder functions. The most common functional deficits were in the ability to sleep comfortably on the side (88 percent unable), throw overhand ( 85 percent unable), wash the back of the opposite shoulder ( 85 percent unable), place 8 pounds on a shelf at head level (76 percent unable), and tuck in the back of a shirt (61 percent unable) (Table 1 , Figure 1).

\section{Health Status}

The general health status of this patient cohort showed significant compromise with respect to the age- and sex-matched control group (Table 2). The greatest compromise was seen in overall comfort (40 percent less than age- and sex-matched control patients) and in physical role function (45 percent less than age- and sex-matched control patients) (Table 2, Figure 2).

\section{Results of Home Management Program Sboulder Function}

Significantly more patients were able to perform the functions of the SST after implementation of the home management program. The greatest improvement was observed in the ability to sleep on the side, wash the back of the opposite shoulder, tuck in the shirt, place hand behind the head with 


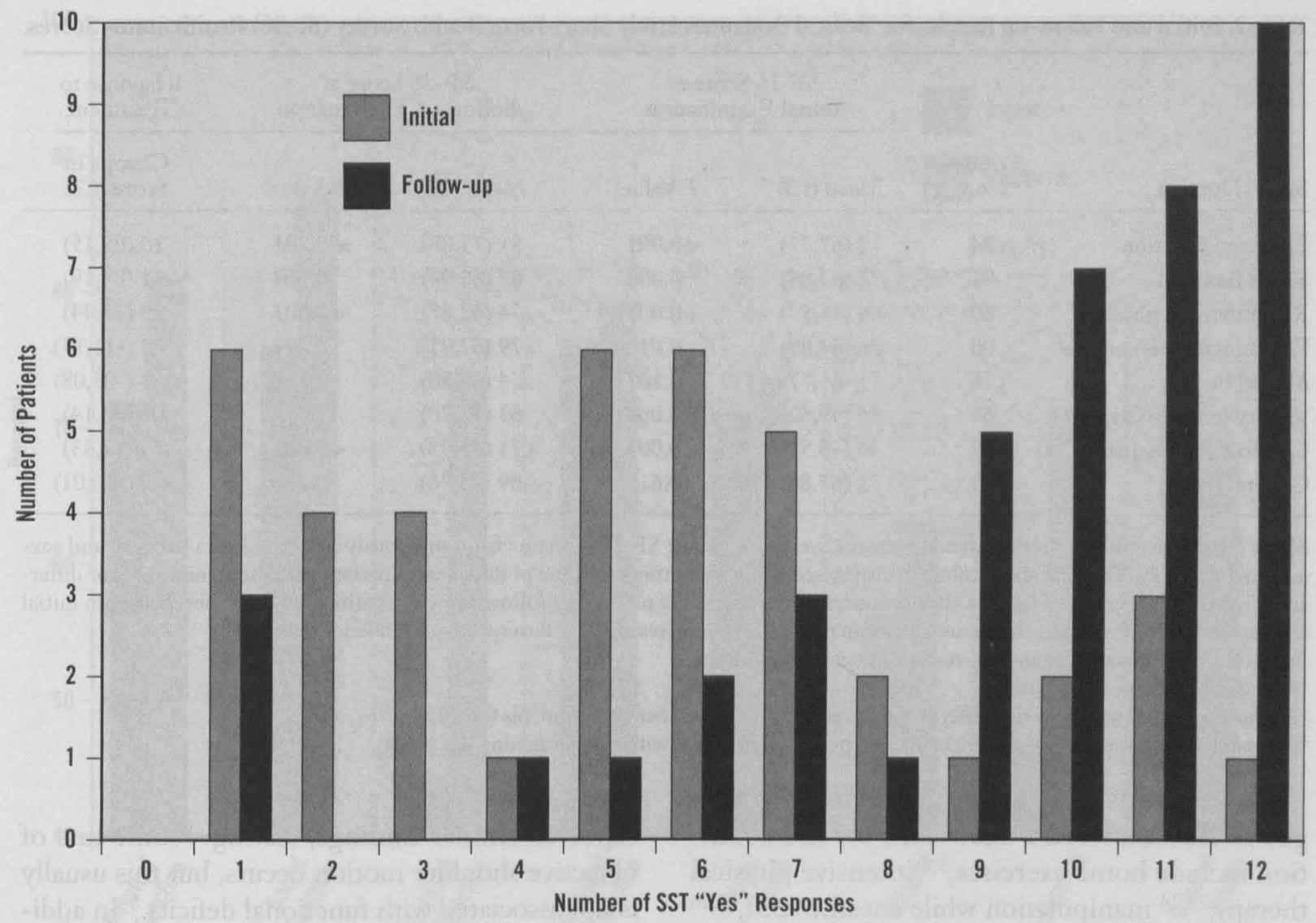

Figure 1. Number of patients with varying "yes" responses to the Simple Shoulder Test (SST) questions at the time of initial and follow-up testing.

the elbow to the side, place 8 pounds on a shelf at head level, and throw overhead. The one function that was not significantly improved was the ability to carry 20 pounds at the side (Table 1, Figure 1).

Thirteen patients improved by at least 6 positive responses, 16 by 3 to 5 responses, 6 patients by 1 to 2 responses. The total number of "yes" answers were unchanged in 3 patients, and another 3 patients had fewer positive responses at follow-up than at the time of initial evaluation. Of the $35 \mathrm{pa}-$ tients whose function improved, 10 answered "yes" to all 12 SST functional questions.

\section{Health Status}

The overall health status as reflected by the SF- 36 showed statistically significant improvement in the domains of physical function, social function, physical role function, and overall bodily comfort (Table 2, Figure 2).

\section{Duration of Follow- $U p$}

There was no significant difference $(P<0.05)$ in the improvement of health status or shoulder function of patients observed for less than 25 months compared with those having more than 25 months of follow-up.

\section{Comorbidities}

Our data did not find statistically significant effects of diabetes, smoking, or bilateral involvement either on the initial shoulder function and health status or on the patients' response to treatment. This particular patient population, however, had a relatively small representation of these conditions; hence, these results might not be representative of populations in which these attributes are more common.

\section{Discussion}

The frozen shoulder has been recognized as a clinically important condition for more than a halfcentury. It has been referred to by a wide variety of names, including adhesive capsulitis, the periarthritic shoulder, and the idiopathic stiff shoulder. ${ }^{2-6,8,22}$ Shoulder stiffness is a common complaint of patients evaluated by orthopedic sur- 
Table 2. Initial and Follow-up Results for Medical Outcomes Study Short-Form Health Survey (SF-36) Health Status Scores.

\begin{tabular}{lcrrrrr}
\hline & & \multicolumn{2}{c}{$\begin{array}{c}\text { SF-36 Score at } \\
\text { Initial Examination }\end{array}$} & $\begin{array}{c}\text { SF-36 Score at } \\
\text { Follow-up Examination }\end{array}$ & $\begin{array}{c}\text { Response to } \\
\text { Treatment }\end{array}$ \\
\cline { 2 - 7 } SF-36 Domain & $\begin{array}{c}\text { Control } \\
\text { Score }\end{array}$ & Mean $(\mathrm{CI})^{\dagger}$ & $P$ Value $^{\ddagger}$ & Mean (CI) & $P$ Value & $\begin{array}{c}\text { Change in } \\
\text { Score (CI) }\end{array}$ \\
\hline Physician function & 84 & $72(67,77)$ & $<0.001$ & $81(75,88)$ & $<0.001$ & $10(05,15)$ \\
Social function & 91 & $76(67,85)$ & 0.002 & $87(80,94)$ & 0.005 & $11(04,19)$ \\
Role function: physical & 80 & $44(31,57)$ & $<0.001$ & $74(62,87)$ & $<0.001$ & $30(17,44)$ \\
Role function: emotional & 90 & $76(64,87)$ & 0.016 & $79(67,91)$ & 0.797 & $02(-11,15)$ \\
Mental health & 76 & $71(65,77)$ & 0.107 & $74(68,80)$ & 0.288 & $03(-03,08)$ \\
Vitality (energy/fatigue) & 62 & $56(49,62)$ & 0.060 & $63(55,70)$ & 0.057 & $07(00,14)$ \\
Comfort (bodily pain) & 77 & $46(40,52)$ & $<0.001$ & $71(63,78)$ & $<0.001$ & $25(17,33)$ \\
General health & 72 & $73(67,80)$ & 0.619 & $69(62,76)$ & 0.116 & $-05(-10,01)$ \\
\hline
\end{tabular}

Note: First data column displays average scores for each of eight SF-36 domains from previously published data for age- and sexmatched-controls. The next three columns display scores for our patients at time of initial examination, with the significance for difference from control values. The next three columns show scores for patients at follow-up with significance for difference from initial scores. Final pair of columns shows net change in each of SF-36 scores along with respective confidence intervals.

${ }^{\star}$ Mean SF-36 scores of age- and sex-matched control population.

$+95 \%$ confidence intervals ( $t$ test).

$\ddagger P$ value that initial scores do not differ from scores of age- and sex-matched controls $(t$ test).

$\S P$ value that follow-up scores are unchanged in pairwise compared with initial examination $(t$ test).

geons. Recommended treatments for this condition include home exercises, ${ }^{3,8}$ intensive physical therapy, ${ }^{23,24}$ manipulation while anesthesized, ${ }^{25,26}$ injection of intra-articular steroids, ${ }^{27,28}$ arthroscopic release, ${ }^{16,29,30}$ and open surgery. ${ }^{8,31}$ Of these treatment regimens, the safest and least expensive is patient education combined with patient-conducted home exercises. The hypothesis tested in the current investigation is that such a simple and economical program can improve shoulder function and general health status as assessed by the patients themselves.

Although reports of the effectiveness of frozen shoulder treatment have traditionally focused on changes in the measured range of motion, $9,10,23,32,33$ the authors of the current study focused instead on the patients' shoulder function and general health status. Several factors led to this decision. From a patient's perspective, the goal of treatment is improvement in comfort, function, and general health status rather than improvement in range of motion measured by a physician or therapist. Furthermore, the correlation between function and range of motion is not uniform. Shaffer et al ${ }^{10}$ found that after the treatment of frozen shoulder, up to 60 percent of patients were left with some residual loss of motion, yet it infrequently affected activities of daily living and caused little functional disability. Miller et $\mathrm{al}^{9}$ reported similar findings, stating: "some loss of objective shoulder motion occurs, but this usually is not associated with functional deficits." In addition, studies using range of motion are subject to observer bias and interobserver variability.

For purposes of comparison, the self-assessment questionnaires used in this study are more easily standardized among practices. Finally, measurement of range of motion requires that the patient return the office for follow-up examinations, inducing potential selection bias in the returning population. This factor is particularly important in the practice studied in this report, because the practice spans a large geographic area. An additional rationale for using patient self-assessment in this study was to demonstrate the usefulness of patient self-assessment tools. Such tools offer individual practicing physicians a practical and inexpensive method to evaluate scientifically the efficacy of their patient treatment plans.

The SF-36 yielded some important and somewhat unexpected results. This general health selfassessment tool found deficits in these patients with frozen shoulder, even though none of the questions of the SF-36 refer specifically to the shoulder. In contrast with previous implications in the literature suggesting that patients with frozen shoulders have a periarthritic personality, ${ }^{34}$ the patients in this population were not particularly 


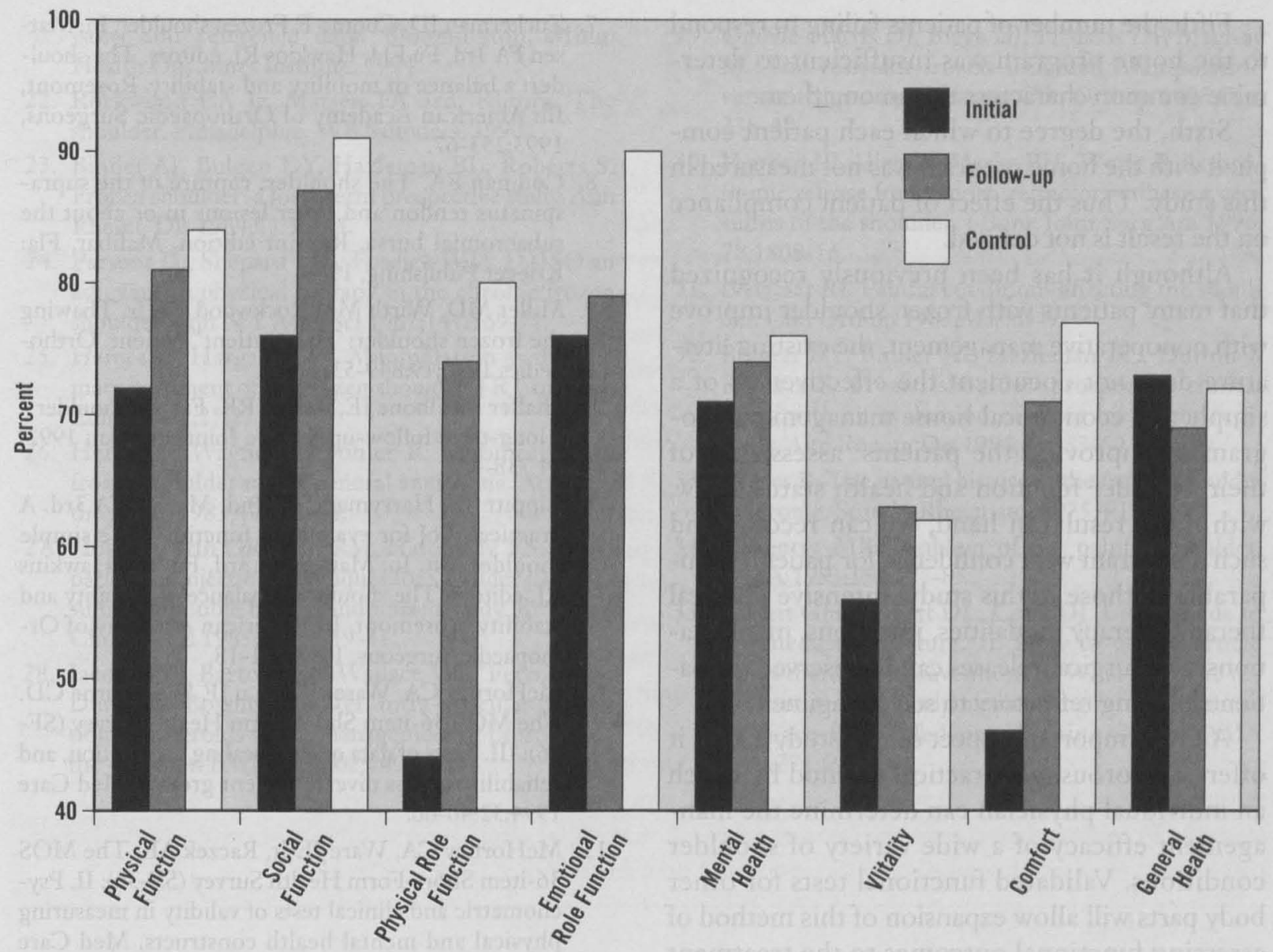

Figure 2. Graph showing the initial and follow-up Short-Form Health Survey (SF-36) scores for the patients and the average scores of an age- and sex-matched control population.

compromised in their self-assessed mental health. Finally, a simple home program for frozen shoulder was associated with a reversal of almost all of the pretreatment SF-36 deficits.

This study has some limitations. First, the patient cohort might not be representative of the patients with frozen shoulder in the general population. That they were referred to a shoulder consultant could suggest their shoulders were more severely involved than those who might seek care from a family physician. On the other hand, because they were not initially selected for more aggressive management (manipulation or surgical release), their shoulders might have been less severely involved. It would be difficult in a primary care practice to accumulate sufficient numbers of patients with frozen shoulder to gather any meaningful data. Our hope is that the readers will be able to use the inclusion criteria, along with the recorded age, sex, initial shoulder function, and overall health status, for this group of patients to recognize similar patients in their practice. ${ }^{35}$

Second, it proved impractical to characterize the nature and extent of each patient's treatment of frozen shoulder before that patient came to our service. The extent of pretreatment varied from none to intensive physical therapy with all gradations in between.

Third, this patient population did not contain sufficient numbers of patients who had diabetes, were smokers, or had other comorbidities to evaluate the influence of these attributes on the initial status or on the response to treatment.

Fourth, we did not contrast the results of this cohort with a matched series of patients receiving no treatment to determine whether our result differed from the natural history of the disease. The findings are nonetheless useful, indicating that for many patients with frozen shoulder, a trial of home stretching often results in major improvements, sparing many from more aggressive, expensive, and higher risk treatments. 
Fifth, the number of patients failing to respond to the home program was insufficient to determine common characteristics among them.

Sixth, the degree to which each patient complied with the home program was not measured in this study. Thus the effect of patient compliance on the result is not defined.

Although it has been previously recognized that many patients with frozen shoulder improve with nonoperative management, the existing literature does not document the effectiveness of a simple and economical home management program in improving the patients' assessment of their shoulder function and health status. Now, with these results in hand, we can recommend such a program with confidence for patients comparable to those in this study. Intensive physical therapy, therapy modalities, injections, manipulations, and surgical releases can be reserved for patients proving refractory to such a regimen.

A final, important aspect of this study is that it offers a rigorous, yet practical method by which an individual physician can determine the management efficacy of a wide variety of shoulder conditions. Validated functional tests for other body parts will allow expansion of this method of assessing functional outcomes to the treatment of a variety of common musculoskeletal complaints. We hope this approach of using self-assessment questionnaires will put effectiveness measurement within the reach of even the busiest physicians.

\section{References}

1. Itoi E, Tabata S. Range of motion and arthrography in frozen shoulders. J Shoulder Elbow Surg 1992; 1:106-12.

2. Matsen FA 3rd, Fu FH, Hawkins RJ, editors. The shoulder: a balance of mobility and stability. Rosemont, Ill: American Academy of Orthopaedic Surgeons, 1993.

3. Matsen FA 3rd, Lippitt SB, Sidles JA, Harryman DT 2nd. Practical evaluation and management of the shoulder. Philadelphia: WB Saunders, 1994.

4. Neviaser JS. Adhesive capsulitis of the shoulder: a study of the pathological finding in periarthritis of the shoulder. J Bone Joint Surg 1945;27:211-22.

5. Neviaser TJ. Adhesive capsulitis. In: McGinty JB, editor. Operative arthroscopy. New York: Raven Press, 1991:561-6.

6. Neviaser TJ. Adhesive capsulitis. In: McGinty JB, editor. Operative arthroscopy. 2 nd ed. Philadelphia: Lippincott, 1996:785-91.
7. Zuckerman JD, Cuomo F. Frozen shoulder. In: Mat- $\frac{D}{3}$ sen FA 3rd, Fu FH, Hawkins RJ, editors. The shoul- एo der: a balance of mobility and stability. Rosemont, Ill: American Academy of Orthopaedic Surgeons, $\frac{2}{7 \pi}$ 1993:253-67.

8. Codman EA. The shoulder: rupture of the supraspinatus tendon and other lesions in or about the subacromial bursa. Reprint edition. Malibar, Fla: Krieger Publishing, 1984.

9. Miller MD, Wirth MA, Rockwood CA Jr. Thawing the frozen shoulder: The "patient" patient. Ortho- $\frac{\bar{c}}{\bar{N}}$ pedics 1996;19:849-53.

10. Shaffer B, Tibone JE, Kerlan RK. Frozen shoulder - के a long-term follow-up. J Bone Joint Surg Am 1992; 74:738-46.

11. Lippitt SB, Harryman DT 2nd, Matsen FA 3rd. A practical tool for evaluating function: The simple shoulder test. In: Matsen FA 3rd, Fu FH, Hawkins RJ, editors. The shoulder: a balance of mobility and stability. Rosemont, Ill: American Academy of Or- N thopaedic Surgeons, 1993:501-18.

12. McHorney CA, Ware JE Jr, Lu JF, Sherbourne CD. O The MOS 36-item Short-Form Health Survey (SF- 윽 36): III. Tests of data quality, scaling assumption, and $\vec{c}$ reliability across diverse patient groups. Med Care 1994;32:40-66.

13. McHorney CA, Ware JE Jr, Raczek AE. The MOS 36-item Short-Form Health Survey (SF-36): II. Psychometric and clinical tests of validity in measuring physical and mental health constructs. Med Care 1993;31:247-63.

14. Ware JE Jr, Sherbourne CD. The MOS 36-item Short-Form Health Survey (SF-36). I. Conceptual framework and item selection. Med Care 1992;30: 473-83.

15. Ware JE Jr, Snow KK, Kosinski M, Gandek B. SF36 health survey, manual and interpretation guide. Boston: The Health Institute, New England Medical Center, 1993.

16. Harryman DT 2nd, Sidles JA, Matsen FA 3rd. Arthroscopic management of refractory shoulder stiffness. J Shoulder Elbow Surg 1996;5(2):112.

17. Matsen FA 3rd. Early effectiveness of shoulder $\widetilde{N}$ arthroplasty for patients who have primary gleno- $\frac{D}{O}$ humeral joint disease. J Bone Joint Surg Am 1996; 78:260-4.

18. Beaton DE, Richards RR. Measuring function of the shoulder. A cross-sectional comparison of five questionnaires. J Bone Joint Surg Am 1996;78:882-90.

19. Romeo AA, Bach BR Jr, O'Halloran KL. Scoring ? systems for shoulder conditions. Am J Sports Med 1996;24:472-6.

20. Stewart AL, Ware JE Jr, editors. Measuring functioning and well-being: the medical outcomes study approach. Durham, NC: Duke University Press, 1992.

21. Radosevich DM, Wetzler H, Wilson SM. Health status questionnaire (HSQ) 2.0: scoring compar- 
isons and reference data. Bloomington, Minn: Health Outcomes Institute, 1994.

22. Rockwood CA Jr, Matsen FA 3rd, editors. The shoulder. Philadelphia: WB Saunders, 1990.

23. Binder AI, Bulgen DY, Hazleman BL, Roberts S. Frozen shoulder: a long-term prospective study. Ann Rheum Dis 1984;43:361-4.

24. Parsons JL, Shepard WL, Fosdick WM. DMSO an adjuvant to physical therapy in the chronic frozen shoulder. Ann N Y Acad Sci 1967;141:569-71.

25. Haines JF, Hargadon EJ. Manipulation as the primary treatment of the frozen shoulder. J R Coll Surg Edinb 1982;27:271-5.

26. Helbig B, Wagner P, Dohler R. Mobilization of frozen shoulder under general anesthesia. Acta Orthop Belg 1983;49:267-74.

27. Hollingworth GR, Ellis RM, Hattersley TS. Comparison of injection techniques for shoulder pain: results of a double blind, randomised study. Br Med J Clin Res Ed 1983;287:1339-41.

28. Jacobs LG, Barton MA, Wallace WA, Ferrousis J, Dunn NA Bossingham DH. Intra-articular distention and steroids in the management of capsulitis of the shoulder. BMJ 1991;302:1498-501.
29. Ogilvie-Harris DJ, Biggs DJ, Fitsialos DP, MacKay $M$. The resistant frozen shoulder. Manipulation versus arthroscopic release. Clin Orthop 1995; Oct: 238-48.

30. Warner JP, Allen A, Marks PH, Wong P. Arthroscopic release for chronic, refractory adhesive capsulitis of the shoulder. J Bone Joint Surg Am 1996; 78:1808-16.

31. Neviaser RJ. Painful conditions affecting the shoulder. Clin Orthop 1983;Mar:63-9.

32. Bulgen DY, Binder AI, Hazleman BL, Dutton J, Roberts S. Frozen shoulder: prospective clinical study with an evaluation of three treatment regimens. Ann Rheum Dis 1984;43:353-60.

33. Reeves $\mathbf{B}$. The natural history of the frozen shoulder syndrome. Scand J Rheumatol 1975;4:193-6.

34. Coventry MB. Problem of the painful shoulder. JAMA 1953;151:177-85.

35. Guyatt GH, Sackett DL, Cook DJ. Users' guide to the medical literature. II. How to use an article about therapy or prevention. B. What were the results and will they help me in caring for my patients? Evidence-Based Medicine Working Group. JAMA 1994;271:59-63. 